\title{
Thiophene-based donor-acceptor conjugated polymer as potential optoelectronic and photonic material
}

\author{
MALUVADI G MURALI ${ }^{1}$, UDAYAKUMAR DALIMBA ${ }^{1, *}$, VANDANA YADAV ${ }^{2}$, \\ RITU SRIVASTAVA $^{2}$ and K SAFAKATH ${ }^{3}$ \\ ${ }^{1}$ Department of Chemistry, National Institute of Technology Karnataka, Surathkal, \\ P.O Srinivasnagar 575 025, India \\ ${ }^{2}$ Organic Light-Emitting Diode Laboratory, Polymeric and Soft Material Division, National Physical \\ Laboratory, New Delhi 110 012, India \\ ${ }^{3}$ Light and Matter Physics Group, Raman Research Institute, C V Raman Avenue, Sadashivanagar, \\ Bangalore 560 080, India \\ e-mail: udayaravi80@gmail.com; udayakumar@nitk.ac.in
}

MS received 24 May 2012; revised 2 August 2012; accepted 10 August 2012

\begin{abstract}
In this paper, we report the synthesis, characterization and optical properties of a donor-acceptor conjugated polymer, PTh-CN, containing 3,4-didodecyloxythiophene and cyanovinylene units. The polymer possesses a low band gap of $1.75 \mathrm{eV}$ as calculated from the onset absorption edge. From the electrochemical study, the HOMO and LUMO energy levels of the polymer are figured out to be $-5.52 \mathrm{eV}$ and $-3.52 \mathrm{eV}$, respectively. Polymer light-emitting diodes are fabricated using PTh-CN as the emissive layer with a device configuration of ITO/PEDOT:PSS/PTh-CN/Al. The device showed stable saturated red electroluminescence with CIE coordinate values $(0.65,0.32)$ at $12 \mathrm{~V}$, which are very close to the values for standard red demanded by the NTSC. In addition, the device showed good colour stability under different bias voltages and the threshold voltage of the PLED device is found to be as low as $3.1 \mathrm{~V}$. Further, a nanocomposite of the polymer and $\mathrm{TiO}_{2}$ nanoparticles is prepared by the dispersion method. The nonlinear optical properties of PTh-CN and PTh-CN/ $\mathbf{T i O} \mathbf{O}_{2}$ nanocomposite are studied using z-scan technique. The polymer solution, polymer film and polymer $/ \mathrm{TiO}_{2}$ nanocomposite film show a strong saturable absorption behaviour. The value of saturation intensity $\left(\mathrm{I}_{\mathrm{s}}\right)$ is found to be of the order $10^{11}-10^{12} \mathrm{~W} / \mathrm{m}^{2}$, indicating that the materials are useful candidates for photonic applications.
\end{abstract}

Keywords. Conjugated polymer; cyclic voltammetry; polymer light-emitting diode; nanocomposite; NLO, z-scan.

\section{Introduction}

In the last two decades, a great deal of attention has been focused on the synthesis of conjugated polymers, ${ }^{1,2}$ because of their significant applications in the field of optoelectronic devices, such as light-emitting diodes (LEDs), ${ }^{3}$ thin film transistors, ${ }^{4}$ chemical sensing, ${ }^{5}$ photovoltaic cells, ${ }^{6}$ optical limiters, etc. ${ }^{7,8}$ In particular, electroluminescent conjugated polymers as active materials in the field of polymer light-emitting diodes (PLEDs) has attracted considerable research interest because these materials are potential candidates in flat-panel display and lighting applications. The main advantage of the conjugated polymers is the colour tunability which can be achieved by changing the mole-

*For correspondence cular structure of the emitting polymers by introducing suitable substituents into the polymer backbone. Hence, the design and synthesis of new conjugated polymers of varied optoelctronic properties play a vital role in the area of display technology. ${ }^{9}$ In this direction, donoracceptor (D-A) conjugated polymers, introduced by Havinga et al. ${ }^{10}$ in the macromolecular systems via alternating electron-rich and electron-deficient substituents along a polymer backbone is the well-known approach to obtain efficient light-emitting polymers. In D-A systems, the interaction between strong electron donor (D) and strong electron acceptor (A) units in the main chain gives rise to an increased double bond character between them. Hence, a conjugated polymer with an alternating sequence of the appropriate donor and acceptor units in the main chain may show a low band gap. ${ }^{11}$ Further, from the application point of view, it is necessary to develop conjugated polymers of pure blue, green and red emission colours for full colour LED 
devices. The cyano $(\mathrm{CN})$ containing poly(2,5-dialkoxy1,4-phenylenevinylene) (CN-DOPPV $)^{12,13}$ and poly(3alkylthiophene) (P3AT) ${ }^{14,15}$ derivatives are known to be good red light-emitting polymers. Several other red light materials have also been reported in the literature. ${ }^{16-19}$ Among these, thiophene derivatives are shown to be good candidates as emissive layer because of their versatility in the structural modification and good semiconducting property. ${ }^{20,21}$ Since the conjugated polymers based on 3,4-dialkoxythiophene derivatives are both electron-rich and hole transporting, it is necessary to introduce electron withdrawing units to the main chains or side chains to attain lower LUMO energy level by increasing the electron affinity of the polymer. The presence of strong electron withdrawing cyano group in the polymer chain has been found to increase the electron affinity and thus enhances the electron injection and hole blocking properties of the polymer. In addition, introduction of cyanovinylene units extend the emission wavelength of the polymer to red and near infrared regions. ${ }^{18,22,23}$

Further, due to the increase in effective electron delocalization along the polymer chain, the D-A conjugated polymers show large third-order nonlinear susceptibilities and hence are a promising class of third-order nonlinear materials. The strong delocalization of $\pi$-electrons in the polymeric backbone determines a very high molecular polarizability and thus remarkable third-order optical nonlinearities. ${ }^{7,24}$ Among various $\pi$-conjugated materials, thiophenebased polymers are currently under intensive investigation as materials for nonlinear optics because of their large third order response, chemical stability, and their readiness of functionalization. Moreover, nano-sized metal and semiconductor particles have attracted considerable interest in many areas such as optics, microelectronics, catalysis, information storage and energy conversion. They exhibit characteristic size and shape dependent electronic structures leading to unique optical and NLO properties. ${ }^{25-28}$ For instance, a third-order NLO susceptibility $\left(\chi^{(3)}\right)$ value of $0.8 \times 10^{-12}$ esu has been observed for yellow Ag colloidal nanoparticles. ${ }^{29}$ Also, a large nonlinear optical response with a $\chi^{(3)}$ value as high as $2 \times 10^{-5}$ esu has been observed for nanoporous layers of $\mathrm{TiO}_{2} \cdot{ }^{28}$ It is advantageous to embed metal/semiconductor nanoparticles in thin polymer films for application purposes because the polymer matrix serves as medium to assemble the nanoparticles and stabilize them against aggregation. ${ }^{30,31}$ Moreover, nanocomposite structures are also known to enhance optical nonlinearities substantially. ${ }^{32}$ In view of these, the third-order NLO optical properties of a few metal/semiconductor-polymer nanocomposites have been investigated. ${ }^{33-35}$ Further, nanocomposites using a few conjugated molecules and oligomers with metal/semiconductor nanoparticles have also been prepared. The effects of the polymer matrix on the optical properties of the nanoparticles and electronic behaviour of both the nanoparticles and conjugated materials have been investigated in these composite materials. ${ }^{36}$ A nonlinear susceptibility of the order of $10^{-7}$ esu and an ultrafast response time of 1.2 ps has been observed for a polymer composite. ${ }^{37}$ Similarly, the nanocomposite made of $\mathrm{Ag}$ nanoparticles dispersed in poly[2-methoxy-5-(2-ethylhexyloxy)-1,4-phenylenevinylene] matrix exhibited large third-order nonlinear susceptibility of the order of $10^{-6}$ esu. ${ }^{38}$ Xin Chen et al. have observed higher $\chi^{(3)}$ value in a polydiacetylene-Ag nanocomposite film compared to pure polydiacetylene film. ${ }^{39}$ However, studies on nanocomposites of donor-acceptor type conjugated polymers and metal/semiconductor nanoparticles are limited. In this context, we describe the synthesis and characterization of a donor-acceptor conjugated polymer, PTh-CN, containing a 3,4-didodecyloxythiophene core (donor) and a cyanovinylene linker (acceptor). Preliminary studies on the electroluminescence properties of the polymer are carried out. Further, the nonlinear optical properties of PTh-CN and $\mathbf{P T h}-\mathbf{C N} / \mathbf{T i O}_{2}$ nanocomposite are studied using z-scan experiment.

\section{Experimental}

\subsection{Instrumentation}

${ }^{1} \mathrm{H}$ NMR spectra were recorded with a BRUKER $400 \mathrm{MHz}$ NMR spectrometer using TMS as internal reference. Elemental analyses were performed on a Flash EA 1112 CHNS analyzer (Thermo Electron Corporation). Infrared spectra of all the compounds were recorded on a NICOLET AVATAR 330 FTIR (Thermo Electron Corporation). UV-Vis absorption spectra were measured using a CINTRA-101 (GBC scientific equipment) spectrophotometer. The electrochemical studies of the polymer were carried out using an AUTOLAB PGSTAT 30 electrochemical analyzer. Cyclic voltammograms were recorded using a three-electrode cell system, with a glass carbon disk as working electrode, a $\mathrm{Pt}$ wire as counter electrode and an $\mathrm{Ag} / \mathrm{AgCl}$ electrode as the reference electrode with $0.1 \mathrm{M}$ tetrabutylammoniumperchlorate (TBAPC) $/ \mathrm{CH}_{3} \mathrm{CN}$ as the electrolyte at a scan rate of $50 \mathrm{mV} / \mathrm{s}$ at room temperature. Fluorescence spectra were recorded using a JASCO FP6200 spectrofluoremeter. Gel permeation chromatography (GPC) was used 
to obtain the molecular weight of the polymer and was determined by Waters make GPC instrument with reference to polystyrene standards with THF as eluent. Polymer and nanocomposite films are prepared using an ACE -1020 (Dong Ah Trade \& Tech. Corp.) spin coating unit. The EL spectrum was determined using HR 2000 Ocean Optics spectrometer, having a CCD array and fibre optic probe. The current-voltage characteristic of the PLED devices was studied using a Keithley 2400 programmable digital source meter. The thickness of the deposited layers was measured by ellipsometry. Thermogravimetric analysis was carried out using an EXSTAR TG/DTA 7000 (SII Nanotechnology Inc.) thermal analyzer. SEM images are obtained with a CARL ZEISS SUPRA 40 VP (NTS GmbH Germany) field emission scanning electron microscopy (FESEM).

\subsection{Materials}

Diethyl 3,4-didodecyloxythiophene-2,5-dicarboxylate (1) was prepared according to the previously reported method. ${ }^{40}$ Lithium aluminum hydride, 2,3-dichloro5,6-dicyano benzoquinone, thiophene-2-acetonitrile, sodium tert-butoxide, poly(3,4-ethylene dioxythiophene):poly(styrene sulphonate) (PEDOT:PSS) and nano-sized $\mathrm{TiO}_{2}$ powder were purchased from Sigma Aldrich Chemical Co. Tetrabutylammoniumperchlorate (TBAPC) was purchased from Lancaster company (UK). All solvents and other reagents were purchased commercially and used without further purification.

\subsection{Synthesis of monomer (Th-CN) and polymer} (PTh-CN)

The synthetic route for preparing the monomer and the polymer are depicted in scheme 1 . The detailed synthetic procedures for the synthesis of the monomer and the polymer are as follows. 2.3a Synthesis of (3,4-bis(dodecyloxy)thiophene-2,5diyl)dimethanol (2): To a solution of diethyl 3,4didodecyloxythiophene-2,5-dicarboxylate, 1, (1 g, $1.67 \mathrm{mmol}$ ) in $10 \mathrm{ml}$ of dry diethyl ether, $0.15 \mathrm{~g}$ $(4.18 \mathrm{mmol})$ lithium aluminum hydride $\left(\mathrm{LiAlH}_{4}\right)$ was added at $0^{\circ} \mathrm{C}$. The reaction mixture was stirred at room temperature for $1 \mathrm{~h}$. After completion of reaction (monitored by TLC), the resulting mixture was quenched with saturated $\mathrm{NH}_{4} \mathrm{Cl}$ solution. The residue obtained was filtered through celite and was washed with dichloro methane. The filtrate thus obtained was washed with water, dried with $\mathrm{MgSO}_{4}$ and concentrated to get the product as white solid in $80 \%$ yield. M.P: $72-73^{\circ} \mathrm{C} .{ }^{1} \mathrm{H}$ NMR $\left(400 \mathrm{MHz}, \mathrm{CDCl}_{3}, \delta, \mathrm{ppm}\right)$ : $4.72\left(\mathrm{~s}, 4 \mathrm{H},-\mathrm{CH}_{2} \mathrm{OH}\right), 4.02\left(\mathrm{t}, \mathrm{J}=6.4 \mathrm{~Hz}, 4 \mathrm{H},-\mathrm{OCH}_{2}\right)$, 1.80-1.26 (m, $\left.40 \mathrm{H},-\left(\mathrm{CH}_{2}\right)_{10^{-}}\right), 0.88(\mathrm{t}, \mathrm{J}=6.8 \mathrm{~Hz}, 6 \mathrm{H}$, $\left.-\mathrm{CH}_{3}\right)$. FTIR, $\sqrt{ }\left(\mathrm{cm}^{-1}\right): 3311(-\mathrm{OH}), 2915$ and 2848 (-C-H), 1500, 1462, 1427, 1364, 1240, 1086, 992. Element. Anal. Calcd. For $\mathrm{C}_{30} \mathrm{H}_{56} \mathrm{O}_{4} \mathrm{~S}$ : C, 70.26; $\mathrm{H}$ 11.01; S, 6.24; found: C, 70.28; H, 11.04; S, 6.22.

2.3b Synthesis of 3,4-bis(dodecyloxy)thiophene-2,5dicarbaldehyde (3): To a solution of compound 2 $(0.5 \mathrm{~g}, 0.97 \mathrm{mmol})$ in $5 \mathrm{ml}$ of dry diethyl ether, $0.66 \mathrm{~g}$ (2.29 mmol) 2,3-dichloro-5,6-dicyanobenzoquinone (DDQ) was added portion-wise at room temperature. The reaction mixture was stirred at room temperature for $72 \mathrm{~h}$. After completion of the reaction (monitored by TLC), the solvent was evaporated. The solid residue obtained was redissolved in $50 \mathrm{ml} n$-hexane and filtered off. The organic layer was washed with water several times, dried with $\mathrm{MgSO}_{4}$ and concentrated. Finally, the obtained crude solid product was recrystallized with ethanol to get the product as white crystals in $60 \%$ yield. M.P: $52-54^{\circ} \mathrm{C} .{ }^{1} \mathrm{H}$ NMR $\left(400 \mathrm{MHz}, \mathrm{CDCl}_{3}, \delta\right.$, ppm): 10.09 (s, 2H, -CHO), 4.26 (t, J = 6.4 Hz, 4H, $\left.-\mathrm{OCH}_{2}\right), 1.83-1.26\left(\mathrm{~m}, 40 \mathrm{H},-\left(\mathrm{CH}_{2}\right)_{10^{-}}\right), 0.88(\mathrm{t}, \mathrm{J}=$ $\left.6.8 \mathrm{~Hz}, 6 \mathrm{H},-\mathrm{CH}_{3}\right)$. FTIR, $\sqrt{ }\left(\mathrm{cm}^{-1}\right): 2914$ and 2848

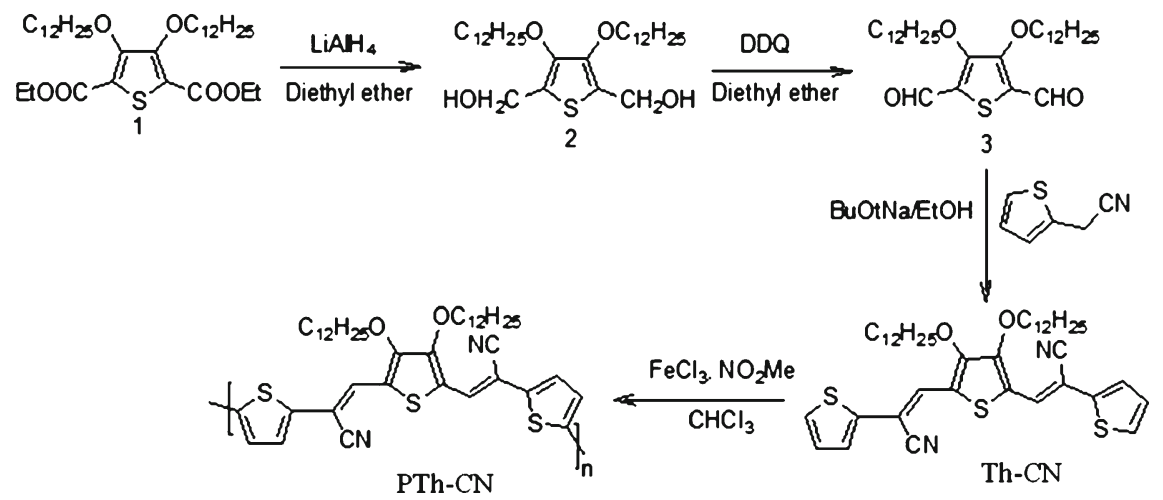

Scheme 1. Synthetic route of the monomer and the polymer. 
$(-\mathrm{C}-\mathrm{H}), 1656(-\mathrm{C}=\mathrm{O}), 1480,1430,1366,1263,1186$, 1037, 798. Element. Anal. Calcd. For $\mathrm{C}_{30} \mathrm{H}_{52} \mathrm{O}_{4} \mathrm{~S}$ : C, 70.82; H, 10.31; S, 6.29; found: C, 70.80; H, 10.34; S, 6.26 .

2.3c Synthesis of 3,3'-(3,4-bis(dodecyloxy)thiophene-2, 5-diyl)bis(2-(thiophen-2-yl)acrylonitrile) (Th-CN): To a stirred solution of dialdehyde $\mathbf{3}(1 \mathrm{~g}, 1.96 \mathrm{mmol})$ and thiophene-2-acetonitrile $(0.5 \mathrm{~g}, 4.12 \mathrm{mmol})$ in $10 \mathrm{ml}$ absolute ethanol under argon, a solution of $0.56 \mathrm{~g}$ of sodium tert-butoxide $(5.89 \mathrm{mmol})$ in $5 \mathrm{ml}$ of absolute ethanol was added through a syringe. The mixture was stirred at room temperature for $2 \mathrm{~h}$. The precipitated solid was filtered off to give dark red shiny solid in $70 \%$ yield. M.P: $89^{\circ} \mathrm{C} .{ }^{1} \mathrm{H}$ NMR $\left(400 \mathrm{MHz}, \mathrm{CDCl}_{3} \delta\right.$, ppm): 7.57 (s, 2H, -olefinic proton-), 7.37-7.35 (dd, $\left.\mathrm{J}_{1}=1.2 \mathrm{~Hz}, 2 \mathrm{H}, \mathrm{J}_{2}=3.6 \mathrm{~Hz}\right), 7.30-7.28\left(\mathrm{dd}, \mathrm{J}_{1}=\right.$ $\left.1.2 \mathrm{~Hz}, \mathrm{~J}_{2}=5.2 \mathrm{~Hz}, 2 \mathrm{H}\right), 7.07-7.05\left(\mathrm{dd}, \mathrm{J}_{1}=4 \mathrm{~Hz}\right.$, $\left.\mathrm{J}_{2}=5.2 \mathrm{~Hz}, 2 \mathrm{H}\right), 4.11\left(\mathrm{t}, 4 \mathrm{H},-\mathrm{OCH}_{2}-\right), 1.80-1.26(\mathrm{~m}$, $\left.40 \mathrm{H},-\left(\mathrm{CH}_{2}\right)_{10^{-}}\right), 0.88\left(\mathrm{t}, 6 \mathrm{H},-\mathrm{CH}_{3}\right)$. FTIR, $\sqrt{ }\left(\mathrm{cm}^{-1}\right)$ : 2913 and 2845 (-C-H), 2205 (-CN), 1568, 1454, 1377, 1282, 1159, 1013, 946. Element. Anal. Calcd. For $\mathrm{C}_{42} \mathrm{H}_{58} \mathrm{~N}_{2} \mathrm{O}_{2} \mathrm{~S}_{3}$ : C, 70.16; H, 8.14; N, 3.90; S, 13.35; found: C, 70.12; H, 8.12; N, 3.86; S, 13.38 .

2.3d Synthesis of polymer (PTh-CN): To a stirred solution of monomer Th-CN (500 mg, $0.695 \mathrm{mmol}$ ) in $50 \mathrm{ml}$ of chloroform was added anhydrous $\mathrm{FeCl}_{3}$ $(0.56 \mathrm{~g}, 3.47 \mathrm{mmol})$ in nitromethane drop-wise over a period of $45 \mathrm{~min}$ at room temperature under argon atmosphere. The light red monomer solution turned progressively dark violet with addition of oxidizing agent. The mixture was stirred for $24 \mathrm{~h}$ and then added into methanol $(200 \mathrm{ml})$. The precipitate was filtered, dissolved in $\mathrm{CHCl}_{3}$, and extracted with water. Solvent was removed and the residue was redissolved in chloroform $(50 \mathrm{ml})$ and hydrazine monohydrate $(25 \mathrm{ml})$. To reduce the polymer to neutral form, the mixture was stirred for $12 \mathrm{~h}$. After evaporation of $\mathrm{CHCl}_{3}$, the residue was precipitated in methanol $(200 \mathrm{ml})$ and filtered off. Then the residue was stirred in acetone to remove unreacted monomers. The polymer was filtered and dried under vacuum to give polymer (PTh-CN) as violet solid. ${ }^{1} \mathrm{H}$ NMR (400 $\left.\mathrm{MHz}, \mathrm{CDCl}_{3}, \delta, \mathrm{ppm}\right)$ : 7.57 (s, 2H, -olefinic proton-), 7.35 (d, J $=3.6 \mathrm{~Hz}$, $2 \mathrm{H}), 7.14(\mathrm{~d}, \mathrm{~J}=4 \mathrm{~Hz}, 2 \mathrm{H}), 4.13$ (t, $4 \mathrm{H},-\mathrm{OCH}_{2}$ ), 1.83-1.23 (m, 40H, $\left.-\left(\mathrm{CH}_{2}\right)_{10^{-}}\right), 0.87\left(\mathrm{t}, 6 \mathrm{H},-\mathrm{CH}_{3}\right)$. FTIR, $\sqrt{ }\left(\mathrm{cm}^{-1}\right): 2912$ and $2846(-\mathrm{C}-\mathrm{H}), 2206(-\mathrm{CN})$, 1567, 1451, 1368, 1260, 1024, 785, 684. Element. Anal. Calcd. For $\mathrm{C}_{42} \mathrm{H}_{56} \mathrm{~N}_{2} \mathrm{O}_{2} \mathrm{~S}_{3}$ : C, 70.36; H, 7.88; N, 3.91; S, 13.39; found: C, 70.28; H, 7.76; N, 3.84; S, 13.48 .

\subsection{Fabrication of the polymer light-emitting diode devices}

In the device fabrication, we used the simplest sandwich structure for the device configuration with poly $(3,4-$ ethylenedioxythiophene):poly(styrenesulphonate) (PEDOT: PSS) coated indium tin oxide (ITO) glass as the anode, the spin coated polymer (PTh-CN) as the emissive layer and aluminum as the cathode. To fabricate PLEDs of device configuration ITO/PEDOT:PSS/PTh$\mathbf{C N} / \mathrm{Al}$, first the indium tin oxide (ITO) coated glass substrates with a sheet resistance of $20 \Omega$ /square and a thickness (ITO) of $120 \mathrm{~nm}$ were cleaned using deionized water, acetone, trichloroethylene and isopropyl alcohol sequentially for about 20 min each using an ultrasonic bath and dried in vacuum oven. Then ITO surface was treated with oxygen plasma for about $5 \mathrm{~min}$ to increase its work function. Then, a hole injection layer of PEDOT:PSS was spin coated on the cleaned and patterned ITO substrates at $4000 \mathrm{rpm}$ with about $50-60 \mathrm{~nm}$ in thickness and was dried by baking at $120^{\circ} \mathrm{C}$ in vacuum for $\sim 1 \mathrm{~h}$. Then, the emitting layer, PTh-CN, was spin cast onto the PEDOT: PSS layer at a speed of $2000 \mathrm{rpm}$ from chlorobenzene solution $(10 \mathrm{mg} / \mathrm{mL})$ through a $0.45 \mu \mathrm{m}$ teflon filter, followed by vacuum annealing at $150^{\circ} \mathrm{C}$ for $\sim 2 \mathrm{~h}$ in order to remove the organic fraction. Finally, the coated ITO was transferred to a deposition chamber, where a layer of $\mathrm{Al}$ electrodes was vacuum deposited on the polymer layer with about $200 \mathrm{~nm}$ in thickness by thermal evaporation at a pressure of $1 \times 10^{-6}$ Torr. Four pixels, each of active area of $4 \times 4 \mathrm{~mm}^{2}$ are defined per substrate and were used to assess the reproducibility of the device performance. The complete fabricated devices were finally annealed at $100^{\circ} \mathrm{C}$ in vacuum for $5 \mathrm{~min}$ before being characterized. All the characterization of the light-emitting diode device was carried out at room temperature under ambient conditions without protective encapsulation.

\subsection{Preparation of $\mathrm{PTh}-\mathrm{CN} / \mathrm{TiO}_{2}$ nanocomposite films}

For the preparation of polymer nanocomposite (PTh$\mathbf{C N} / \mathbf{T i O}_{2}$ ) films, 10 weight $\% \quad \mathrm{TiO}_{2}$ nanoparticles were dispersed in the polymer using chloroform and chlorobenzene solvent system (10:1 volume ratio) and sonicated for $2 \mathrm{~h}$. Nanocomposite films are prepared on clean glass plates by spin coating and the films are dried under vacuum for $1 \mathrm{~h}$.

\subsection{Z-Scan measurements}

The z-scan technique is a widely used method developed by Sheik Bahae et al. ${ }^{41}$ to measure the nonlinear 
absorption coefficient and nonlinear refractive index of materials. The 'open aperture' z-scan gives information about the nonlinear absorption coefficient. A nearly Gaussian laser beam is used for optically exciting the sample, and its propagation direction is considered as the $\mathrm{z}$-axis. The beam is focused using a convex lens and the focal point is taken as $z=0$. Obviously, the beam will have maximum energy density at the focal point, which will symmetrically reduce towards either side of it, for the positive and negative values of $\mathrm{z}$. In the experiment the sample is placed in the beam at different positions with respect to the focus (i.e., at different values of $\mathrm{z}$ ), and the corresponding optical transmission values are measured. Then a graph is plotted between $\mathrm{z}$ and the measured sample transmission (normalized to its linear transmission), which is known as the $\mathrm{z}$-scan curve. The shape of the z-scan curve will provide information on the nature of the nonlinearity. The nonlinear absorption coefficient of sample can be calculated by fitting the experimental data to theory.

In our z-scan experiment, we have used a steppermotor controlled linear translation stage, to move the sample through the beam in precise steps. Two pyroelectric energy probes (Rj7620, Laser Probe Inc.) are used to measure the transmission of the sample at each point. One energy probe monitors the input energy, while the other monitors the transmitted energy through the sample. The second harmonic output $(532 \mathrm{~nm})$ of a Q-switched Nd:YAG laser ( Minilite- Continuum, $5 \mathrm{~ns}$ FWHM laser pulses) was used for excitation of samples. The linear transmissions of the samples studied were in the range of $50 \%$ to $75 \%$ at $532 \mathrm{~nm}$. The experiments were carried out in the 'single shot' mode, allowing sufficient time between successive pulses to avoid accumulative thermal effects in the sample. The experiment was automated, controlled by a data acquisition program written in Lab VIEW.

\section{Results and discussion}

\subsection{Synthesis and characterization}

The synthetic method followed for the synthesis of monomer Th-CN and polymer PTh-CN is depicted in scheme 1. 3,4-Bis(dodecyloxy)thiophene-2,5-dicarbaldehyde (3) was synthesized starting from diethyl 3,4-didodecyloxythiophene-2,5-dicarboxylate (1). The diester compound (1) was reduced using lithium aluminum hydride in ether at room temperature to obtain (3,4-bis(dodecyloxy)thiophene-2,5-diyl)dimethanol (2). The bisalcohol (2) was then oxidized to the dicarbaldehyde (3), using 2,3-dichloro-5,6-dicyano-1,4-benzoquinone as the oxidizing agent. In the next step, a Knoevenagel condensation reaction was performed between 3,4-bis(dodecyloxy)thiophene-2,5-dicarbaldehyde (3) and thiophene-2-acetonitrile in ethanol in the presences of sodium tert-butoxide under argon atmosphere to yield the monomer, Th-CN. The overall yields for all the intermediate compounds were between 60 and $80 \%$. Polymer PTh-CN was prepared by the chemical oxidation of the monomer (Th-CN) using $\mathrm{FeCl}_{3}$ as oxidizing agent. This method is very useful to prepare polythiophenes due to its simplicity and the high molecular weights achieved. After the polymerization reaction, the residual iron (III) salts present in the mixture were reduced in concentration with rigorous purification. The crude polymer obtained was precipitated with methanol several times in order to remove residual $\mathrm{FeCl}_{3}$. The oxidative polymerization reaction gives the polymer in the oxidized (doped) form. The reduction (dedoping) of the polymer was achieved using hydrazine to get the polymer in the neutral form. Further, the polymer was stirred with acetone so as to remove any traces of unreacted monomer. All the intermediate compounds and the polymer showed good solubility in common organic solvents, such as $\mathrm{CHCl}_{3}$, THF and chlorobenzene, resulting from the alkoxy chains at 3 and 4 - positions of the thiophene ring. The chemical structures of all the intermediate compounds and the polymer were confirmed by ${ }^{1} \mathrm{H}$ NMR spectroscopy, FTIR spectroscopy and elemental analysis. The ${ }^{1} \mathrm{H}$ NMR spectrum of monomer $\mathbf{T h}-\mathbf{C N}$ showed a singlet at $\delta 7.57 \mathrm{ppm}$ which is assigned to the olefinic protons. The three double doublet peaks in the range of $\delta$ 7.37-7.35, 7.07-7.05 and 7.30-7.28 ppm are assigned to thiophene ring protons at position 2,3 and 4 , respectively. The triplet peak at $\delta 4.11 \mathrm{ppm}$ is due to $-\mathrm{OCH}_{2}-$ protons of the alkoxy chains of the thiophene ring and the multiple peaks in the range $\delta 1.80-0.88 \mathrm{ppm}$ are due to $-\left(\mathrm{CH}_{2}\right)_{10}-\mathrm{CH}_{3}$ protons of the alkoxy chains. Polymerization of the monomer Th-CN was confirmed by the ${ }^{1} \mathrm{H}$ NMR spectrum. In the ${ }^{1} \mathrm{H}$ NMR spectrum, the disappearance of double doublet peak of thiophene ring proton at position 2 and conversion of double doublet in to a doublet peak gave a clear evidence of successful polymerization of the monomer to the polymer. The ${ }^{1} \mathrm{H}$ NMR spectrum of polymer PTh-CN showed a singlet at $\delta 7.57 \mathrm{ppm}$ due to olefinic protons. The two doublet peaks at $\delta 7.35$ and $7.14 \mathrm{ppm}$ are assigned to thiophene ring protons at positions 3 and 4 , respectively. A triplet peak at $\delta 4.13 \mathrm{ppm}$ is due to the $-\mathrm{OCH}_{2}-$ protons of the alkoxy chains of the thiophene ring and the multiple peaks in the range $1.83-0.87 \mathrm{ppm}$ are due to the $-\left(\mathrm{CH}_{2}\right)_{10}-\mathrm{CH}_{3}$ protons of the alkoxy chains. The average molecular weights of the polymer were measured by gel permeation chromatography (GPC) with 
reference to polystyrene standards. The number averaged molecular weight $\left(\mathrm{M}_{\mathrm{n}}\right)$ of the polymer is found to be 15800 and the molecular weight distribution (PDI) is 2.1 . Generally, the chemical polymerization method gives polymers with high molecular weights. But, the average molecular weights of PTh-CN are rather low. This could be due to the presence of strong electron withdrawing cyano group in the monomer, which deactivates thiophene ring towards oxidative polymerization reaction. This effect becomes more prominent in the growing polymer chain due to increase in the number cyano groups with successive addition of the repeating units. As a result, further addition of monomeric units becomes difficult which terminates the polymerization process. Hence a low molecular weight polymer sample is obtained in the present study. The strong bands at 2912 and $2846 \mathrm{~cm}^{-1}$ in the FTIR spectrum of PTh-CN are due to $(\mathrm{C}-\mathrm{H})$ stretching vibrations of the alkyl chains. The band at $2206 \mathrm{~cm}^{-1}$ is assigned to the $-\mathrm{C} \equiv \mathrm{N}$ stretching vibration. FTIR spectrum of the $\mathrm{TiO}_{2}$ nanoparticles exhibits a band at $3397 \mathrm{~cm}^{-1}$ due to $\mathrm{O}-\mathrm{H}$ stretching mode of $\mathrm{Ti}-\mathrm{OH}$. The characteristic absorption band of Ti-O-Ti was observed at $475 \mathrm{~cm}^{-1} .{ }^{42}$ All these characteristic bands arising from both $\mathrm{TiO}_{2}$ nanoparticles and PTh-CN were observed in the spectrum of PTh-CN/ $/ \mathbf{T i O}_{2}$ nanocomposite, confirming the incorporation of $\mathrm{TiO}_{2}$ nanoparticles in the nanocomposite structure. ${ }^{43}$ Smooth and optically clear thin solid films on glass substrates were obtained by spin-coating the chloroform solutions of the polymer $\left(1 \mathrm{mg} \mathrm{mL}^{-1}\right)$ at a spin rate of $1500 \mathrm{rpm}$. Figure 1 shows the FESEM image of the PTh-CN/TiO ${ }_{2}$ nanocomposite. A moderately uniform distribution of $\mathrm{TiO}_{2}$ nanoparticles was observed with average particle sizes ranging from 25 to $50 \mathrm{~nm}$. The thickness of polymer films and nanocom-

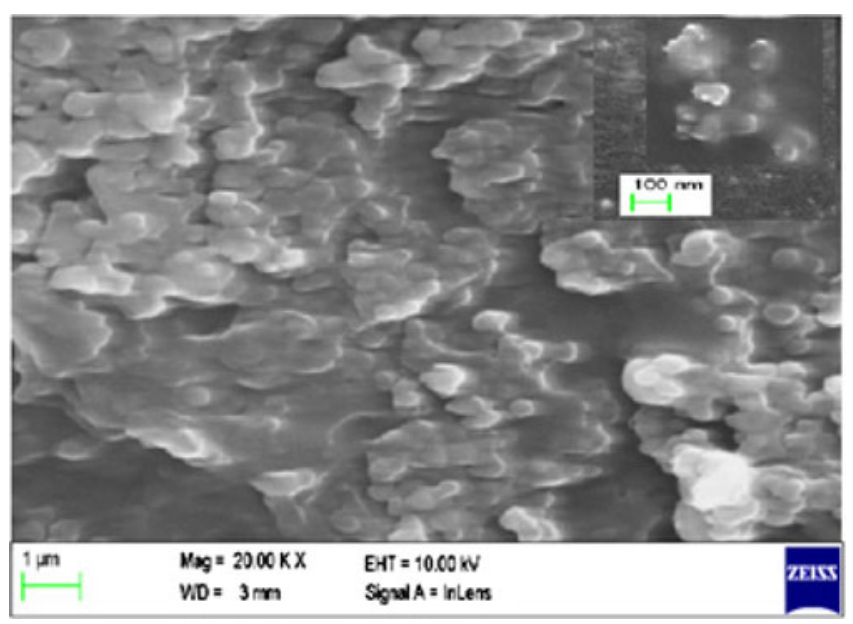

Figure 1. FESEM images of $\mathbf{P T h}-\mathbf{C N} / \mathbf{T i O}_{2}$ nanocomposite (inset: magnified image, Mag $=100 \mathrm{KX}$ ). posite films were determined by SEM cross section and was found to be in the range $0.9-1$ micrometer.

\subsection{UV-Vis absorption studies}

The UV-Vis absorption spectra could provide a good deal of information on the electronic structure of conjugated polymers. Figure 2 shows the absorption spectra of monomer Th-CN and polymer PTh-CN in dilute chloroform solution along with the spectra of PTh-CN thin film and PTh-CN/TiO $\mathbf{T}_{2}$ nanocomposite thin film. The monomer solution displayed an absorption maximum at $457 \mathrm{~nm}$, where as for the polymer solution an absorption maximum is observed at $550 \mathrm{~nm}$. The monomer being a donor-acceptor conjugated molecule shows absorption in the visible region. The presence of alternating electron withdrawing and electron releasing units in a conjugated system results in strong intramolecular charge transfer (ICT) interactions, which extends the absorption to longer wavelength regions. The polymer thin film, in addition to an absorption maximum at $550 \mathrm{~nm}$, showed a peak in the shorter wavelength region at $390 \mathrm{~nm}$ and a shoulder at $661 \mathrm{~nm}$. The optical energy band gap $\left(\mathrm{E}_{\mathrm{g}}\right)$ of PTh-CN is found to be $1.75 \mathrm{eV}$ in the thin film state. The broadening of the absorption spectrum of the polymer film in comparison with that of the polymer solution could be due to the enhanced interchain interaction in the solid film state and increased polarizability of the film. The absorption spectra of PTh-CN/TiO $\mathbf{2}$ nanocomposite thin film showed a red shift of about $18 \mathrm{~nm}$ in comparison with that of the polymer film. The observed

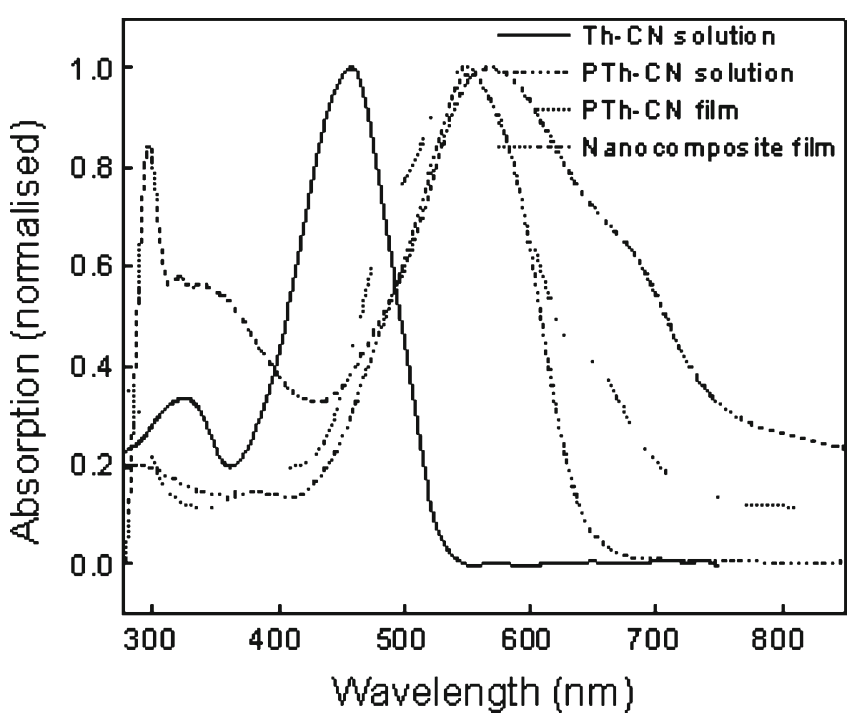

Figure 2. UV-Vis absorption spectra of Th-CN solution, PTh-CN in chloroform solution, PTh CN thin film and PTh$\mathbf{C N} / \mathbf{T i O}_{2}$ nanocomposite thin film. 
Table 1. Linear optical and nonlinear optical properties of the polymer.

\begin{tabular}{|c|c|c|c|c|c|c|c|}
\hline & \multicolumn{4}{|c|}{ Linear optical properties $\lambda_{\max }(\mathrm{nm})$} & \multicolumn{3}{|c|}{ Nonlinear optical properties (z- scan) $I_{\mathrm{s}}$ in $\mathrm{W} / \mathrm{m}^{2}$} \\
\hline & Solution $^{\mathrm{a}}$ & Film ${ }^{b}$ & $\begin{array}{l}\text { Nanocomposite } \\
\text { filmb }^{\mathrm{b}}\end{array}$ & $\mathrm{E}_{\mathrm{g}}^{\mathrm{opt}} \mathrm{eV}$ & Solution $^{\mathrm{a}}$ & Film $^{\mathrm{b}}$ & $\begin{array}{l}\text { Nanocomposite } \\
\text { film }^{\mathrm{b}}\end{array}$ \\
\hline PTh-CN & 550 & 550 & $568(295)$ & 1.75 & $2 \times 10^{12}$ & $6 \times 10^{11}$ & $9 \times 10^{11}$ \\
\hline
\end{tabular}

${ }^{\mathrm{a}}$ Measured in chloroform solution. ${ }^{\mathrm{b}}$ Cast from chloroform solution

$\mathrm{E}_{\mathrm{g}}^{\mathrm{opt}}$, Bandgap estimated from the onset wavelength of the optical absorption of the polymer film

$I_{s}$ Saturation intensity measured from z-scan technique

red shift in the absorption maximum can be understood in terms of enhanced effective $\pi$-conjugation length in $\mathbf{P T h}-\mathbf{C N} / \mathbf{T i O}_{2}$ nanocomposite film as compared to that of PTh-CN film. A similar trend in the absorption maximum was observed for $\mathrm{MEH}-\mathrm{PPV} / \mathrm{TiO}_{2}$ nanocomposite films. ${ }^{44}$ Further, the peak observed at $295 \mathrm{~nm}$ in the nanocomposite film is assigned to the characteristic absorptions of $\mathrm{TiO}_{2}$ nanoparticles. These optical results indicate that some interactions occur between the conjugated polymer chains and $\mathrm{TiO}_{2}$ nanoparticles. The optical properties of PTh-CN are summarized in table 1 .

\subsection{Thermal stability}

The thermal property of polymer PTh-CN and PTh$\mathbf{C N} / \mathbf{T i O}_{2}$ nanocomposite were determined by thermogravimetric analysis (TGA) and was carried out under nitrogen atmosphere at a heating rate of $10^{\circ} \mathrm{C} / \mathrm{min}$. The TGA reveals that, both the polymer and the nanocomposite possess good thermal stability. The onset decomposition temperature for the polymer was observed near $180^{\circ} \mathrm{C}$ with a gradual weight loss until $320^{\circ} \mathrm{C}$, which could be attributed to the loss of alkoxy or alkyl chains present on the thiophene ring. Beyond this temperature range, the weight loss increases abruptly, indicating the decomposition of the polymer backbone. The nanocomposite is thermally stable up to $300^{\circ} \mathrm{C}$. When the temperature is increased beyond $300^{\circ} \mathrm{C}$, there is a sharp weight loss near $350^{\circ} \mathrm{C}$ and it continues until $650^{\circ} \mathrm{C}$. Similar trend was observed for other nanocomposites reported in the literature. ${ }^{43}$ These results indicate that there is a strong interaction exists at the interface of the polymer and $\mathrm{TiO}_{2}$ nano particles in the nanocomposite structure.

\subsection{Electrochemical properties}

The device fabrication and investigation of LED characteristics of polymers require information on the electronic structure of the luminescent polymer which can be determined by electrochemical studies. Cyclic voltammetry was used to investigate the redox behaviour of the polymer and to assess the HOMO and LUMO energy levels. All measurements were calibrated with the ferrocene/ferrocenium $\left(\mathrm{Fc} / \mathrm{Fc}^{+}\right)$standard $\left(\mathrm{E}_{\mathrm{FOC}}=0.53\right.$ vs. $\left.\mathrm{Ag} / \mathrm{AgCl}\right)$. As shown by the cyclic voltammogram in figure 3 , the polymer showed both $n$-doping and $p$-doping processes. On sweeping the polymer cathodically, the onset of the $n$-doping process occurred at a potential value of $-0.75 \mathrm{~V}$ with a reduction peak at $-1.06 \mathrm{~V}$. In the anodic scan, the $p$ doping onset was observed at $1.25 \mathrm{~V}$ followed by an oxidation peak at $1.55 \mathrm{~V}$. The onset potentials of $n$ doping and $p$-doping processes were used to estimate the HOMO and LUMO energy levels of the conjugated polymer according to the equations; ${ }^{45}$

$$
\begin{aligned}
& \mathrm{E}_{\text {Hомо }}=-\left[\mathrm{E}_{\text {(onset) }}^{\text {ox }}+4.8 \mathrm{eV}\right] \text { and } \\
& \mathrm{E}_{\text {LUMO }}=-\left[\mathrm{E}_{\text {(onset) }}^{\text {red }}+4.8 \mathrm{eV}\right],
\end{aligned}
$$

where $\mathrm{E}_{\text {(onset) }}^{\mathrm{ox}}$ and $\mathrm{E}_{\text {(onset) }}^{\mathrm{red}}$ are the onset potentials for the oxidation and reduction processes of a polymer, respectively. Accordingly, the HOMO and LUMO energy

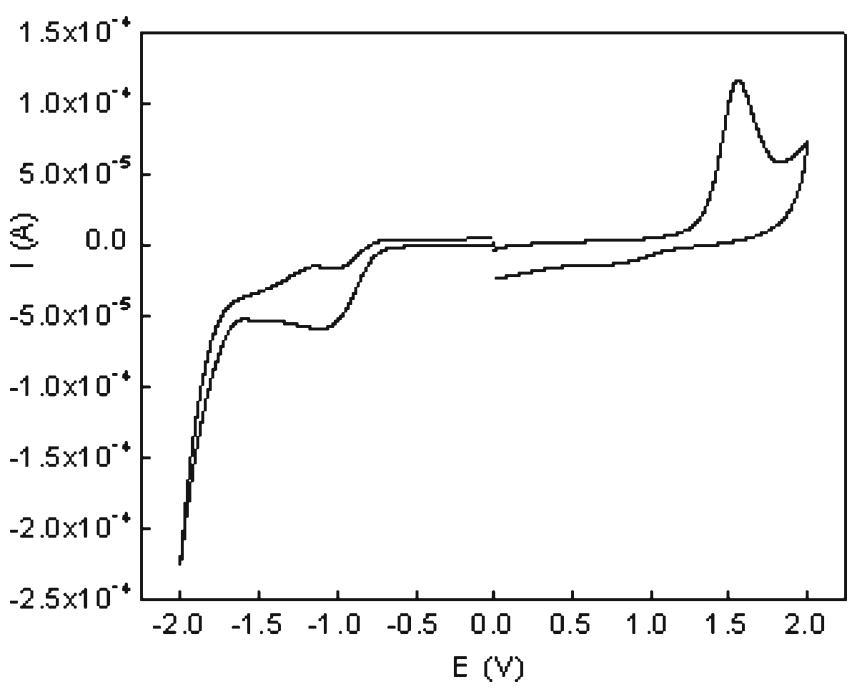

Figure 3. Cyclic voltammogram of the polymer film cast on glassy carbon disk in $0.1 \mathrm{M}$ tetrabutylammoniumperchlorate (TBAPC) $/ \mathrm{CH}_{3} \mathrm{CN}$ solution at $50 \mathrm{mV} / \mathrm{s}$. 
Table 2. Electrochemical properties of the polymer.

\begin{tabular}{cccccccc}
\hline Polymer & $\mathrm{E}_{\text {(onset) }}^{\mathrm{ox}}(\mathrm{V})$ & $\mathrm{E}(\mathrm{oxd})(\mathrm{V})$ & $\mathrm{E}_{\text {(onset) }}^{\text {red }}(\mathrm{V})$ & $\mathrm{E}(\mathrm{red})(\mathrm{V})$ & $\mathrm{HOMO}(\mathrm{eV})$ & LUMO $(\mathrm{eV})$ & $\mathrm{E}_{\mathrm{g}}(\mathrm{eV})$ \\
\hline PTh-CN & 1.25 & 1.55 & -0.75 & -1.06 & -5.52 & -3.52 & 2.0 \\
\hline
\end{tabular}

$\mathrm{E}_{\mathrm{g}}^{\mathrm{Ec}}$ Electrochemical band gap estimated from the difference between $\mathrm{E}_{\mathrm{HOMO}}$ and $\mathrm{E}_{\mathrm{LUMO}}$

levels of the polymer are estimated to be $-5.52 \mathrm{eV}$ and $-3.52 \mathrm{eV}$, respectively and hence electrochemical band gap of the polymer is $2.0 \mathrm{eV}$. The electrochemical band gap of the polymer is higher than the optical band gap. This difference is due to the creation of free ions in the electrochemical experiment compared with the one measured through UV experiments, which refers to a neutral state. From the high electron affinity value, which could be attributed to the electron withdrawing property of $-\mathrm{CN}$ units in the polymer backbone, it can be expected that the polymer may show increased electron injection ability in PLEDs. Also, the electrochemical data support the argument that the injection of electrons and holes would be more balanced in the polymer. The cyclic voltammetry data of the polymer are summarized in table 2 .

\subsection{Fluorescence emission and electroluminescence properties}

Fluorescence emission studies of Th-CN and PTh-CN reveal that $\mathbf{T h}-\mathbf{C N}$ and $\mathbf{P T h}-\mathbf{C N}$ in dilute chloroform solution emit intense green and red light, respectively, under the irradiation of UV light with emission maxima at $550 \mathrm{~nm}$ for Th-CN and $657 \mathrm{~nm}$ for PTh-CN. The fluorescence quantum yield $\left(\phi_{\mathrm{fl}}\right)$ of the polymer in chloroform solution was estimated by comparing with the standard of quinine sulphate (ca. $1 \times 10^{-5} \mathrm{M}$ solution in $0.1 \mathrm{M} \mathrm{H}_{2} \mathrm{SO}_{4}$ having a fluorescence quantum yield of $55 \%) .{ }^{46}$ The quantum yield of the polymer is $38 \%$.

PLED devices fabricated with a configuration of ITO/PEDOT:PSS/PTh-CN/Al were used to investigate the electroluminescent (EL) behaviour of the polymer (PTh-CN) as emissive material for polymer light emitting diodes. The devices are fabricated under ambient conditions and are characterized without using any protective encapsulation. The EL spectra of polymer PTh-CN under different driving voltages ranging from $7 \mathrm{~V}$ to $14 \mathrm{~V}$ are as shown in figure 4. The EL spectra show that with an increase in the applied voltage, the intensity of the emitted light also increases as a function of wavelength. The PLED devices emitted red light with emission maxima originated at 615 and $670 \mathrm{~nm}$. Also, the EL spectrum of the polymer showed stable red emission without any considerable spectral change and/or additional peaks with driven voltage. The EL spectra of the polymer was blue shifted relative to the corresponding PL spectra which results from different exciton generation processes and heating of the LEDs because of applied voltages during the measurement. This suggests that the local heating in the polymer film at high voltages probably leads to conformational changes of the polymer backbone. The colour stability under different voltages for PTh-CN was also investigated. The CIE coordinates of the polymer devices under different voltages of $11 \mathrm{~V}, 12 \mathrm{~V}, 13 \mathrm{~V}$ and $14 \mathrm{~V}$ were $(0.64,0.32)$, $(0.65,0.32),(0.66,0.32)$ and $(0.64,0.32)$, respectively. The EL peak position and the CIE coordinates of the device were not changed significantly under different driving voltages. These results indicate that the polymer show good colour stability under different applied voltages. The colour coordinates of the red emitting PTh$\mathbf{C N}$ is closer to the standard red $(0.66,0.34)$ demanded by the National Television System Committee (NTSC) indicating that $\mathbf{P T h}-\mathbf{C N}$ emits almost pure red colour. ${ }^{47}$ The current density-voltage characteristics of the PLED device (figure 5) show that the current density of the polymer increases exponentially with the increasing forward bias voltage, which is a typical diode characteristic. The polymer shows low threshold voltage of $3.1 \mathrm{~V}$. The lower threshold voltage can be attributed to the lower energy barrier for electron injection (due to

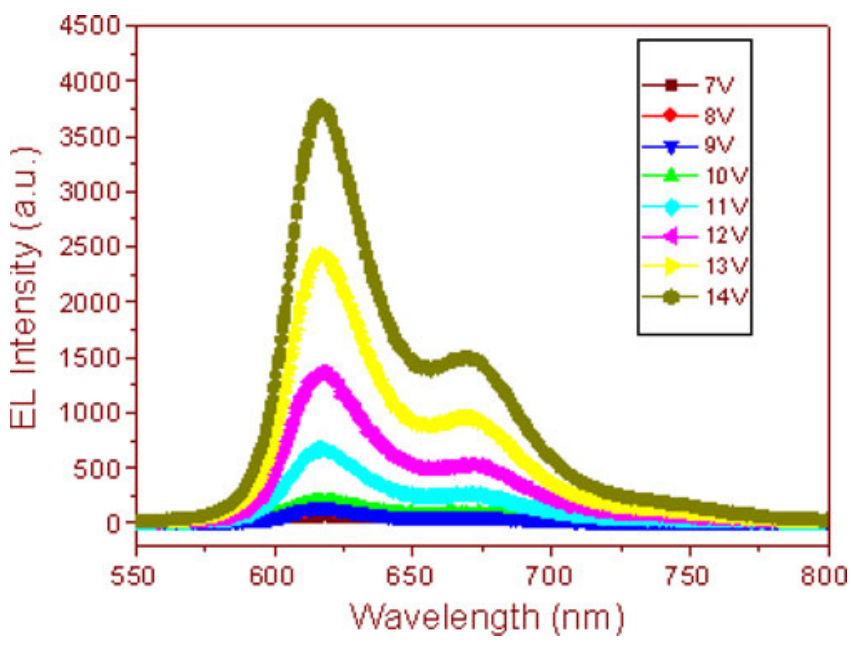

Figure 4. Electroluminescence (EL) spectra of the ITO/PEDOT: PSS/ PTh-CN/Al device at varying forward applied voltages. 


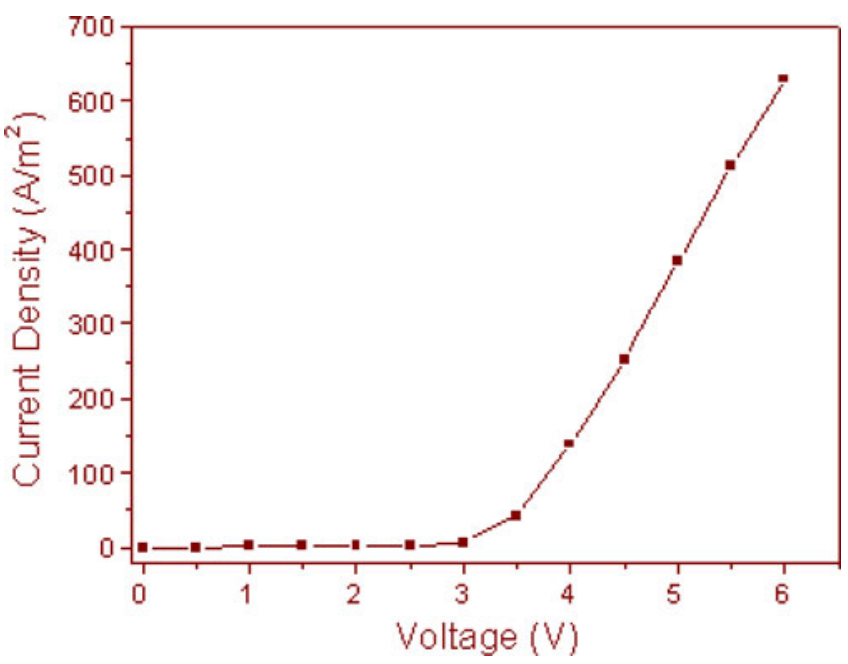

Figure 5. Current density-voltage characteristics of the ITO/PEDOT: PSS/ PTh-CN/Al device.

low lying LUMO level of the polymer) from the aluminum electrode. The low threshold voltage value can be comparable with some of the previously reported light-emitting polymers which showed good EL performance. ${ }^{23}$ These preliminary studies on EL properties of PTh-CN suggest that the polymer may be used for the fabrication of stable red light-emitting diodes.

\subsection{Nonlinear optical properties}

The open aperture z-scan curves obtained in the polymer PTh-CN solution, PTh-CN film and PTh$\mathbf{C N} / \mathbf{T i O}_{2}$ film are shown in figures 6,7 and 8 , respectively. The laser pulse energies used to excite the samples were between 10 and $100 \mu \mathrm{J}$. All samples show a pure saturable absorption (SA) behaviour.

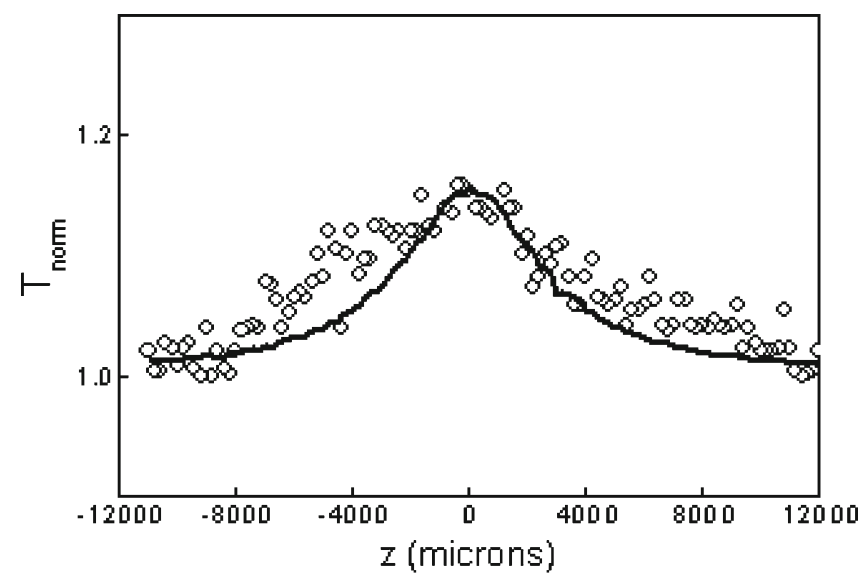

Figure 6. Open aperture z-scan of PTh-CN in solution having a linear transmission of $51 \%$ at $532 \mathrm{~nm}$. The laser pulse energy is $100 \mu \mathrm{J}$. Circles are data points while the solid curve is a numerical fit according to Eq. 1.

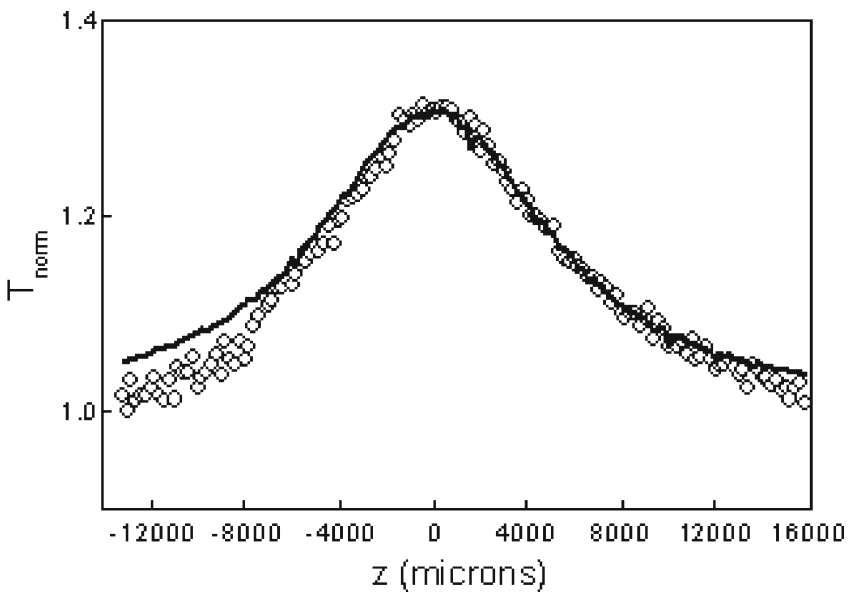

Figure 7. Open aperture z-scan of PTh-CN film having a linear transmission of $72 \%$ at $532 \mathrm{~nm}$. The laser pulse energy is $10 \mu \mathrm{J}$. Circles are data points while the solid curve is a numerical fit according to Eq. 1.

Saturable absorption is a property of a material where the absorption of light decreases with the increase of light intensity. At sufficiently high incident light intensity, atoms or molecules in the ground state of a saturable absorber material become excited into upper energy state at such a rate that there is insufficient time for them to decay back to the ground state before the ground state becomes depleted, and the absorption subsequently saturates. In a saturable absorber, the nonlinear absorption coefficient $\alpha$ is given by,

$$
\alpha=\alpha_{0} \frac{1}{1+\left(\frac{I}{I_{\mathrm{s}}}\right)},
$$

where $\alpha_{0}$ is the linear absorption coefficient at the wavelength of excitation, $I$ is the incident intensity,

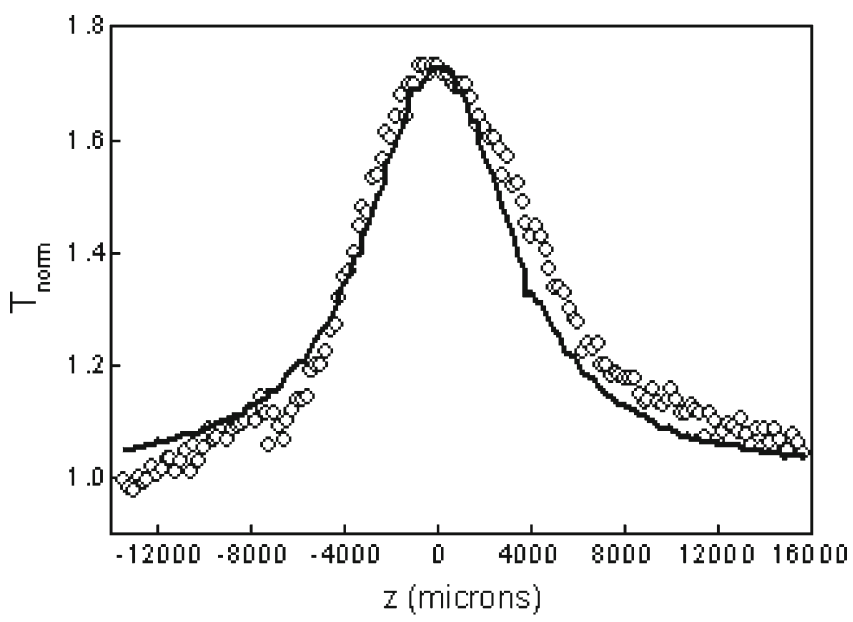

Figure 8. Open aperture z-scan of $\mathbf{P T h}-\mathbf{C N} / \mathbf{T i O}_{\mathbf{2}}$ film having a linear transmission of $50 \%$ at $532 \mathrm{~nm}$. The laser pulse energy is $10 \mu \mathrm{J}$. Circles are data points while the solid curve is a numerical fit according to Eq. 1. 
and $I_{s}$ is the saturation intensity. The z-scan profile usually shows a valley with a maximum and a minimum on each side of the focal point. However, in our study, the open aperture z-scan profile shows a typical peak, symmetric about the focus, which is known to be the signature of saturable absorption behaviour. The peak appears at the focal point where the laser pulse has the strongest fluence. A similar type of saturable absorption in the near-field transmission was observed for inorganic materials. ${ }^{48}$ The z-scan curves obtained are fitted with numerically simulated results using Eq. (1). By determining the best-fit curves for the experimental data, the nonlinear parameters could be calculated. For PTh-CN solution, saturation intensity $\left(I_{s}\right)$ was found to be $2 \times 10^{12} \mathrm{~W} / \mathrm{m}^{2}$, for PTh$\mathbf{C N}$ film it was $6 \times 10^{11} \mathrm{~W} / \mathrm{m}^{2}$ and for PTh-CN/TiO 2 nanocomposite film it was found to be $9 \times 10^{11} \mathrm{~W} / \mathrm{m}^{2}$. Obviously there is an enhancement of nonlinearity in PTh-CN/TiO ${ }_{2}$ nanocomposite film compared to pure PTh-CN film. This is not substantial though, the reason being that the polymer films themselves are highly nonlinear in nature. From a device point of view both PTh-CN and PTh-CN/TiO $\mathbf{~}_{2}$ nanocomposite films are equally useful. Because of their large saturable absorption, both PTh-CN and PTh-CN/TiO $\mathbf{T}_{2}$ nanocomposite films are expected to be useful candidates for photonic applications mainly in the areas such as Q- switching and mode-locking of lasers, pulse shaping, and optical switching. ${ }^{49}$ For comparison, similar saturable absorption behaviour is observed for some organic materials in the literature. The values of $\mathrm{I}_{s}$ obtained are 1.5 to $4.5 \times 10^{13} \mathrm{~W} / \mathrm{m}^{2}$ in phthalocyanines, 1 to $4 \times$ $10^{10} \mathrm{~W} / \mathrm{m}^{2}$ in poly(indenofluorene), $10^{10}$ to $10^{11} \mathrm{~W} / \mathrm{m}^{2}$ for Rhodamine B and 1.4 to $6.8 \times 10^{13} \mathrm{~W} / \mathrm{m}^{2}$ for thiophene-based conjugated polymers. ${ }^{50-53}$ The value of $\mathrm{I}_{s}$ obtained for PTh-CN is almost 100 times lower than the values obtained for thiophene-based donoracceptor polymers, ${ }^{53}$ indicating a better NLO response in PTh-CN. This could be due to the presence of stronger electron withdrawing cyano group in PTh$\mathbf{C N}$ in comparison with 1,3,4-oxadiazole groups in the reported polymers. The nonlinear optical properties of the polymer are summarized in table 1 . The presence of strong electron donor and electron acceptor groups in the polymer chain increases $\pi$-electron delocalization and hence improves the NLO properties of the polymer. Thus, incorporation of cyano groups as electron acceptors in donor-acceptor conjugated polymers could be a promising molecular design to achieve high NLO responses in polymers. Further, nanocomposite structures formed by the incorporation of $\mathbf{T i O}_{2}$ nanoparticles into the polymer matrix found to enhance the NLO properties of the polymer. Hence donor-acceptor con- jugated polymers and their nanocomposites could be potential candidates for photonic applications.

\section{Conclusions}

A donor-acceptor type conjugated polymer, PTh-CN containing 3,4-didodecyloxythiophene unit as electron donor moiety and cyanovinylene unit as electron acceptor moiety was synthesized and characterized. The push-pull (D-A) arrangement along with the presence of strong electron withdrawing cyano group in the polymer structure greatly influenced its electronic structure. Hence the polymer showed a lower bandgap with a low-lying LUMO energy level. As a result, the polymer light-emitting device based on PTh-CN showed a low threshold voltage of $3.1 \mathrm{~V}$ indicating an efficient electron injection in the device. Further, the polymer device showed almost pure red emission with a CIE coordinate of $(0.65,0.32)$, which is very close to the standard red. Also, the device, without any protective encapsulation, showed good colour stability under different bias voltages. The PTh-CN/TiO $\mathbf{T}_{2}$ nanocomposite was prepared using the dispersion method. Incorporation of $\mathbf{T i O}_{2}$ nanoparticles into the polymer matrix found to improve the thermal stability of the polymer. The nonlinear optical properties of PTh-CN and PTh-CN/TiO $/ 2$ nanocomposite are studied using z-scan technique. All the samples show a strong saturable absorption behaviour and the incorporation $\mathrm{TiO}_{2}$ nanoparticle marginally enhances the nonlinear optical property in PTh-CN/TiO ${ }_{2}$ nanocomposite film when compared to the pure PTh-CN film. The NLO results signify that the materials are useful candidates for photonic applications.

\section{Supplementary information}

The electronic supporting information can be seen in www.ias.ac.in/chemsci.

\section{Acknowledgements}

Authors from the National Institute of Technology Karnataka (NITK) thank Dr. Reji Philip, Raman Research Institute (RRI), Bangalore for providing facility for z-scan studies.

\section{References}

1. Skotheim T A, Elsenbaumer R L and Reynolds J R 1998 Handbook of conducting polymers (New York: MarcelDekker) 
2. Mullen K and Wegner G 1998 Electronic materials, the oligomer approach (Weinheim, Germany: Wiley-VCH)

3. Burroughes J H, Bradley D D C, Brown A R, Marks R N, Mackay K, Friend R H, Burn P L and Holmes A B 1990 Nature 347539

4. Li Y, Wu Y and Ong B S 2006 Macromolecules 396521

5. Mcquade D T, Pullen A E and Swager T M 2000 Chem. Rev. 1002537

6. Yu G, Gao J, Hummelen J C, Wudl F and Heeger A J 1995 Science 2701789

7. Prasad P N and David J W 1991 Introduction to nonlinear optical effects in molecules and polymers (New York: Wiley)

8. Kishino S, Ueno Y, Ochiai K, Rikukawa M, Sanui K, Kobayashi T, Kunugita H and Ema K 1998 Phys. Rev: B. 5813430

9. Choi M C, Kim Y and Ha C S 2008 Prog. Polym. Sci. 33 581

10. Havinga E E, Hoeve W and Wynberg H 1993 Synth. Met. 55299

11. Colladet K, Fourier S, Cleji T J, Laurence L, Gelan J and Vanderzande D 2007 Macromolecules 4065

12. Greenham N C, Moratti S C, Bradley D D C, Friend R H and Holmes A B 1993 Nature 365628

13. Liu Y, Yu G, Li Q and Zhu D 2001 Synth. Met. 122401

14. Berggren $M$, Inganäs $\mathrm{O}$, Gustaffusson $\mathrm{G}$, Rasmusson $\mathrm{J}$, Andersson M R, Hjertberg T and Wennerström O 1994 Nature (London) 372444

15. Andersson $M \mathrm{R}$, Berggren $\mathrm{M}$, Inganäs $\mathrm{O}$, Gustaffusson G, Gustafsson-Carberg J C, Selec D, Hjertberg T and Wennerström O 1995 Macromolecules 287525

16. Cho N S, Park J H, Lee S K, Lee J and Shim H K 2006 Macromolecules 39177

17. Chen C H, Klubek K P and Shi J 1999 U.S. Patent 5908581

18. Kim J H and Lee H 2002 Chem. Mater. 142270

19. Guo Z S, Zhao L, Pei J, Zhou J L, Gibson G, Brug J, Lam S and Samuel S M 2010 Macromolecules 431860

20. Roncali J 1997 Chem. Rev. 97173

21. Barbarella G, Melucci M and Sotigu G 2005 Adv. Mater. 171581

22. Kim J H and Lee H 2003 Synth. Met. 139471

23. Egbe D A M, Kietzke T, Carbonnier B, Muhlbacher D, Horhold H H, Neher D and Pakula T 2004 Macromolecules 378863

24. Kiran A J, Udayakumar D, Chandrasekharan K, Adhikari A V and Shashikala H D 2006 J. Phys. B: At. Mol. Opt. Phys. 393747

25. SujithKumar G and Tarasankar P 2007 Chem. Rev. 107 4797

26. Venkatram N, Rao D N and Akundi M A 2005 Opt. Express 13867

27. Philip R, Ravindrakumar G, Sandhyarani N and Pradeep T 2000 Phys. Rev: B. 6213160
28. Gayvoronsky V, Galas A, Shepelyavyy E, Dittrich T, Timoshenko V Y, Nepijko S A, Brodyn M S and Koch F 2005 Appl. Phys. B $\mathbf{8 0} 97$

29. Chen X, Zou G, Deng Y and Zhang Q 2008 Nanotechnology 19195703

30. Boyd R W, Gehr R J, Fischer G L and Sipe J E 1996 Pure. Appl. Opt. 5505

31. Takele H Greve H, Pochstein C, Zaporojtchenko V and Faupel F 2006 Nanotechnology 173499

32. Neeves A E and Birnboim M H 1988 Opt. Lett. 131087

33. Porel S, Venkataram N, Rao D N and Radhakrishnan T P 2007 J. Appl. Phys. 10233107

34. Gao Y, Tonizzo A, Walser A, Potasek M and Dorsinville R 2008 Appl. Phys. Lett. 9233106

35. Karthikeyan B, Anija M and Philip R 2006 Appl. Phys. Lett. 8853104

36. Sih B C and Wolf M O 2005 Chem. Commun. 3375

37. Hu X Y, Jiang P, Ding C Y, Yang H and Gong Q H 2008 Nat. Photonics. 2185

38. Hu X, Zhang J, Yang H and Gong Q 2009 Opt. Express 1718858

39. Chen X, Tao J, Zou G, Zhang Q and Wang P 2010 Appl. Phys. A. 100223

40. Zhong Q T and Tour J M 1998 J. Am. Chem. Soc. 120 5355

41. Sheik-Bahae M, Said A A, Wei T H, Hagan D J and Van Stryland E W 1990 IEEE J. Quantum Electron 26760

42. Music S, Gotic M, Ivanda M, Popovic S, Turkovic A, Trojko R, Sekulic A and Furic K 1997 Mater. Sci. Eng. B. 4733

43. Zhu Y, Xu S, Jiang L, Pan K and Dan Y 2008 React. Funct. Polym. 681492

44. Yang S H, Rendu P L, Nguyen T P and Hsu C S 2007 Rev. Adv. Mater. Sci. 15144

45. De Leeuw D M, Simenon M M J, Brown A B and Einerhand R E F 1997 Synth. Met. 8753

46. Joshi H S, Jamshidi R and Tor Y 1998 Angew. Chem. Int. Ed. 382721

47. Gunter W and Stiles W S 1982 Color science: Concepts and methods, quantitative data and Formulae, 2nd ed. (New York: John Wiley and Sons)

48. Cassano T, Tommasi R, Tassara M, Babudri F, Cardone A, Farinola G M and Naso F 2001 Chem. Phys. 272111

49. Davies B L and Samoc M 1997 Curr. Opin. Solid State Mater. Sci. 2213

50. Venkatram N, Rao D N, Giribabu L and Rao S V 2008 Chem. Phys. Lett. 464211

51. Samoc M, Samoc A and Davies B L 1988 Opt. Lett. 23 1295

52. Venkatram N, Naga Srinivas N K M and Rao D N 2002 Chem. Phys. Lett. 361439

53. Hegde P K, Adhikari A V, Manjunatha M G, Suchand Sandeep C S and Philip R 2011 Adv. Polym. Tech. 30312 